\title{
Educación laica: ¿Por qué y Para qué?
}

Secular education: Why and for what?

Dr. Juan Javier Morales

García

Profesor de educación media superior. Doctor en Educación por el Instituto Superior de Ciencias de la Educación del Estado de México (ISCEEM). Email: lagranmole@hotmail.com

Dr. Liberio Victorino Ramírez

Profesor Investigador, Universidad Autónoma Chapingo (UACh). Investigador Nacional por el Sistema Nacional de Investigadores del Conacyt de México. Email:

Recibido

07/ 09/2018

Revisado 09/09/2018

Aceptado 04/10/2018

\section{RESUMEN}

o que se presenta a continuación forma parte de una investigación titulada "Las potencialidades de la _educación laica en la escuela primaria" (2010, ISCEEM, Toluca, México) basada en la teoría del nuevo paradigma cultural de Alain Touraine, así como en los aportes de los principales representantes de la laicidad como son Henri Peña, Jean Bauberot y Roberto Blancarte. Para este artículo se presentan algunas reflexiones en torno al tema de la laicidad en la educación pública mexicana, su significado, sus interpretaciones, las batallas culturales en torno a ella y sobre todo, sus potencialidades en la formación ciudadana en la educación básica. Su objetivo consiste en abordar los cinco aspectos más relevantes que la formación en la laicidad puede proveer y que, por mucho, rebasan los beneficios que pudiera otorgar cualquier clericalismo en la educación pública. Se concluye que dicha laicidad promueve la igualdad y el bien común que son también base de la democracia; además, al promover la libertad de conciencia capacita a los agentes para la toma de decisiones basados en la crítica y la reflexión, indispensables para la democracia.

Palabras clave: Educación pública, escuela primaria, laicidad, multiculturalidad, democracia. 


\section{ABSTRACT}

The following document is part of a research entitled "Potentialities of laïc education in primary school" based on the Alain Touraine's theory of the new cultural paradigm as well as the contributions of the main representatives of laïcite like Henri Peña, Jean Bauberot and Roberto Blancarte. This writing submits some reflections about the topic of laïcite en mexican public education, its meaning, its interpretation, the cultural battles arpund it and above all, their potentialities on citizen formation in primary school.

Key Words: Public education, primary school, laicity, multiculturalism, democracy. 


\section{INTRODUCCIÓN}

C riticada por algunos e incomprendida por muchos, la educación laica ofrece beneficios para el mejoramiento de la vida en sociedad, principalmente donde se ha impuesto una determinada convicción espiritual o filosófica, y se rechaza, discrimina y condena cualquier otro tipo de creencia.

La educación laica no es únicamente una educación ajena a cualquier doctrina religiosa, sino también, una educación sustentada en principios que implican profunda consideración de la libertad y de la justicia. La laicidad, que ha sido incomprendida, relegada y desaprovechada debido a generalizadas concepciones equivocadas, posee grandes potencialidades para la formación del ciudadano, una vez que se ha comprendido e interiorizado su esencia. En el presente escrito, se muestran los cinco aspectos más relevantes que la formación en la laicidad puede proveer y que, por mucho, rebasan los beneficios que pudiera otorgar cualquier clericalismo en la educación pública.

En la primera parte se muestra a la laicidad como promotora de la formación para y en la democracia, señalando el origen común de la laicidad y la democracia, así como la interrelación que existe entre ambas.

La laicidad se analiza en la segunda parte, como un elemento esencial de lo que los autores han denominado "valores laicos" como una propuesta en la formación de valores en los que todos nos podemos identificar sin importar la creencia religiosa 0 filosófica que se tenga.

La tercera potencialidad es la formación del pensamiento crítico-reflexivo que, como resultado de la libertad de conciencia que provee la laicidad, lleva a los agentes escolares a reflexionar y a desarrollar la capacidad de decisión de cambiar 0 permanecer, basada en una liberación de toda sujeción impuesta o inducida, aspecto necesario para el ejercicio pleno de la democracia.

La cuarta potencialidad está relacionada con la formación del agente escolar en el discernimiento entre los ámbitos público y privado, necesarios para determinar lo que es de alguno de lo que es de todos, considerado base de la tolerancia y de la aceptación de la diversidad.

Por último, se propone a la laicidad como un elemento que fortalece la identidad nacional basada en aspectos multiculturales, en los que todos nos podamos sentir 
identificados, independientemente de las preferencias religiosas o filosóficas de los agentes escolares.

\section{1. ¿Qué es la laicidad?}

¿La laicidad está en contra de la religión? ¿La laicidad carece de utilidad en una sociedad multicultural? ¿Es otra convicción más? ¿Cómo las religiones o las filosofías?

Responder a estas preguntas requiere del conocimiento pleno de la laicidad, desde sus orígenes etimológicos, sus fundamentos y usos, hasta los elementos con los que se interrelaciona. Existen muchas ideas acerca de la laicidad, como la conocida adjetivación atea o la hostilidad a la religión; otras más han sido creadas bajo conceptos que en ocasiones están muy alejados de los fundamentos laicos.

El Papa Benedicto XVI, el 17 de diciembre de 2006, en el 56 Congreso Nacional de la unión de juristas católicos italianos, reconoció este problema al mencionar que este congreso afrontaba el tema de la laicidad, de gran interés porque pone de relieve que en el mundo de hoy la laicidad se entiende de varias maneras; pues, existen múltiples formas de entender y vivir la laicidad, maneras a veces opuestas e incluso contradictorias entre sí.

Debido a la existencia de diversos conceptos de laicidad, surge la necesidad de conocer su significado a partir de los elementos que la conforman y sus principios filosóficos. La laicidad tuvo su origen en Francia desde el último tercio del siglo XIX en la educación el general, particularmente, como escuela laica, obligatoria y gratuita. Esto sucedió a partir de la Guerra franco-prusiana y la llegada de la III República al poder (Blancarte como se citó en Gutiérrez, 2006, p.149). Dicha laicidad surgió como el resultado de una lucha por el establecimiento de la libertad de conciencia, reprimida hasta entonces.

De acuerdo a Peña, "la laicidad se refiere al principio de unificación de los hombres en el seno del Estado; supone una distinción jurídica entre la vida privada del hombre como tal y su dimensión pública como ciudadano, y en su vida privada en su vida personal, como el hombre adopta una convicción espiritual -religiosa o no- que puede compartir naturalmente con otros" (Peña, 2002, p. 11).

El origen etimológico de laicidad que muestra Henri Peña nos permite comprender los elementos esenciales que la conforman. Laicidad viene del griego laos que designa 
la unidad de una población considerada como un todo indivisible. La unidad del laos es así un principio de igualdad. Y esta igualdad se basa en la libertad de conciencia, la cual es reconocida como primaria. La conciencia no puede ni debe ser violentada, ella adoptará una convicción o confesión libremente.

La unidad del laos ha de entenderse en oposición a la idea de que un grupo particular, al destacarse, se otorgue más derechos, incluso un papel rector dentro del conjunto: El laos, no tiene otro fundamento que la igualdad de convicciones; impide que una confesión particular se vuelva una norma general y se constituya en la base de un poder sobre la totalidad" (Peña, 2002, p.18). El origen de laicidad es de la unidad del pueblo bajo el principio de igualdad y libertad que, en esencia, es la libertad de conciencia, la cual no está sometida a ningún credo obligado.

En una comunidad laica, el ateísmo, agnosticismo, monoteísmo o politeísmo son opciones donde todos se reconocen en igualdad y la opción espiritual sigue siendo asunto privado. Ahora bien, el ámbito privado de lo religioso no es exclusivo de lo personal e individual sino también de lo colectivo que no lo transforma a público. Los asuntos de carácter privado realizados en colectivo como las religiones no pueden ser nunca del ámbito público; ya que, este último está relacionado con la vida en común de una sociedad. En el ámbito público, se expresan todas las ideas relacionadas con la vida en común como son las leyes bajo las cuales todos vivimos sin excepción en un territorio dado, o la educación que se imparte en una escuela pública donde se reúnen alumnos y docentes con diferentes concepciones ideológicas; pero con un fin común, respetando las convicciones personales que pertenecen al ámbito privado, como son las religiones o cualquier otro tipo de convicción filosófica.

La Constitución Política de los Estados Unidos Mexicanos es un conjunto de leyes comunes a todos los connacionales de México, en ella se aprecia un establecimiento de derechos y obligaciones, por lo tanto, se ubica como parte del ámbito público; pues implica a todos los ciudadanos. Por otro lado, el Catecismo católico y la Biblia, que también son un conjunto de señalamientos y decretos; son de carácter estrictamente particular aunque no necesariamente individual, ya que, pueden ser colectivos; pero no pueden considerárseles como parte del ámbito público debido a que también existen otras religiones y filosofías compartiendo ese espacio.

Henri Peña afirma que el bien común viene del término res pública que a su vez originó el de república. La república, por esencia, busca el bien común como norma de convivencia social y este incluye, en primer lugar, la libertad de todos en un pueblo 
soberano que se otorga a sí mismo su propia ley y donde la obediencia no tiene nada que ver con la sumisión o la servidumbre. El bien común incluye en primer lugar la libertad de todos y el rechazo de toda discriminación confesional.

Los principios de la laicidad proceden de una concepción de la dignidad humana. Libertad de conciencia, Igualdad de derechos, bien común más allá de las diferencias, confianza de principio en la autonomía, afirmación simultánea de la soberanía de la conciencia individual y del pueblo sobre sí mismo; es todo un ideal que resuena en la palabra laicidad. (Peña, 2002, p.20)

La laicidad, como afirmación de independencia de la vida espiritual, sería efectivamente un principio de unión que eleva a los hombres, tratando de emanciparlos de los límites del lugar, del momento y de las normas inducidas por los poderes temporales (Peña, 1999). Otros teóricos que han expresado su interés en el tema de la laicidad coinciden en varios de los aspectos que Peña señala. Roberto Blancarte, por ejemplo, menciona que laicidad es un régimen social de convivencia, cuyas instituciones políticas están legitimadas principalmente por la soberanía popular ${ }^{1}$ y ya no por elementos religiosos (Blancarte, 2000, p. 124). El referido autor identifica una parte esencial de la laicidad; pues, se refiere a ella como un régimen social de convivencia, puesto que no es una forma más de pensamiento sino una forma de vida que permite la existencia de variadas formas de pensamiento.

Touraine (2005), por su parte, analiza a la laicidad en el marco de la sociedad multicultural francesa, afirmando lo siguiente:

...el laicismo fue y es un elemento esencial de lo que se puede llamar el espíritu republicano, es decir, el descubrimiento de criterios de evaluación de los individuos y las instituciones en términos de bien común, de interés público, de patriotismo, de normas sociales dominantes, y también de racionalidad del ser. (p.164)

Añade a lo anterior que el principio de laicismo prolonga el reconocimiento de los derechos personales al plantear la autonomía de la sociedad política con relación a los principios y las prácticas de las religiones. Touraine enfatiza que "en una sociedad multicultural los derechos culturales corresponden a derechos de diferencia más que a derechos de igualdad" (Touraine, 2005. p.209). 
En todo caso, resultaría muy difícil hablar de derechos culturales más que cuando las conductas culturales y sociales piden ser reconocidas en nombre del derecho de cada uno a practicar su propia cultura, su lengua, su religión, sus relaciones de parentesco, sus costumbres alimentarias, entre otras. Para Touraine el multiculturalismo "...es la combinación de una unidad social y una pluralidad cultural en un territorio dado, lo que supone reconocer elementos de unidad entre las culturas."Touraine, como se citó en Gutiérrez, (2006, p. 279). Uno de esos elementos de unidad es la laicidad, en palabras de Touraine, es: "La única sociedad multicultural estable es el estado laico, secularizado, lo que llamamos democracia." En México, la presencia de diferentes convicciones religiosas y filosóficas es un indicativo innegable de una sociedad multicultural cada vez más conformada en la pluralidad.

El llamado al multiculturalismo fue y es ante todo una protesta contra la hegemonía de categorías que se identificaban con lo universal e imponían su dominación a aquellos a quienes consideraban sus inferiores por el hecho de estar encadenados a sus particularidades. De ahí que Touraine afirme: "No hay multiculturalismo sin laicidad" (Touraine, como se citó en Gutiérrez (2006 p. 299).

Actualmente, la laicidad busca el pleno ejercicio de las libertades individuales, no únicamente la libertad religiosa; aunque, en sus inicios la lucha fue contra la imposición ejercida por la jerarquía católica, sin embargo, esto no quiere decir que esta sea su consigna perpetua. La lucha por la libertad de conciencia y por la liberación del sometimiento ideológico religioso caracterizó a los primeros movimientos de la laicidad, de ahí que los clericalismos busquen encasillarla como antirreligiosa 0 incluso atea. La laicidad es una forma de vida basada en la libertad de conciencia², el bien común, la igualdad y el respeto a la diferencia; define los límites entre los ámbitos público y privado, por lo que promueve todas las expresiones, ya sean espirituales o filosóficas, y se opone a todo intento por imponer y tratar de establecer una hegemonía en la heterogeneidad. La laicidad no es una convicción más entre las posibilidades existentes; es una forma de vida que promueve la existencia de convicciones en un marco de igualdad e imparcialidad.

Existen múltiples beneficios que la laicidad y la educación laica pueden aportar a la conformación de una sociedad que busque la convivencia en la diferencia. A continuación se presenta cinco de las principales potencialidades para la vida en una sociedad plural y democrática. 


\section{La laicidad para el fortalecimiento de la democracia}

Una de las más grandes responsabilidades de los estados democráticos es la educación. En México, la escuela ha cumplido con la misión de educar y formar a los ciudadanos, siendo el Estado el encargado de elegir los criterios sobre los cuales se orientará la educación tanto pública como privada. Actualmente, tales criterios se encuentran plasmados en el artículo tercero constitucional, donde destacan las fracciones I y II:

I. Garantizada por el artículo 24 la libertad de creencias, dicha educación será laica y, por tanto, se mantendrá por completo ajena a cualquier doctrina religiosa;

II. El criterio que orientará a esa educación se basará en los resultados del progreso científico, luchará contra la ignorancia y sus efectos, las servidumbres, los fanatismos y los prejuicios.

Además:

a) Será democrático, considerando a la democracia no solamente como una estructura jurídica y un régimen político, sino como un sistema de vida fundado en el constante mejoramiento económico, social y cultural del pueblo;

b) Será nacional, en cuanto — sin hostilidades ni exclusivismos - atenderá a la comprensión de nuestros problemas, al aprovechamiento de nuestros recursos, a la defensa de nuestra independencia política, al aseguramiento de nuestra independencia económica y a la continuidad y acrecentamiento de nuestra cultura, y

c) Contribuirá a la mejor convivencia humana, tanto por los elementos que aporte a fin de robustecer en el educando, junto con el aprecio para la dignidad de la persona y la integridad de la familia, la convicción del interés general de la sociedad, cuanto por el cuidado que ponga en sustentar los ideales de fraternidad e igualdad de derechos de todos los hombres, evitando los privilegios de razas, de religión, de grupos, de sexos o de individuos; (Constitución Política de los Estados Unidos Mexicanos, 2015)

Estos criterios muestran los elementos de una formación democrática enfocada a contribuir a una mejor convivencia humana, al aprecio por la dignidad de la persona, al interés general de la sociedad, a la igualdad y la no discriminación por motivos de raza, sexo o religión; haciendo hincapié en mostrar a la democracia como un sistema de vida más allá de la simple concepción jurídica y política. 
El artículo tercero constitucional muestra una relación intrínseca entre los elementos conceptuales de la democracia y la laicidad. En griego, hay dos palabras distintas para designar al pueblo: laos y demos. Laos ha dado laicidad, principio de derecho que vincula el poder público al conjunto del pueblo; vinculación liberadora que prohíbe cualquier puesta en tutela de unos hombres por otros. Demos ha dado democracia, tipo de organización política que expresa la soberanía del pueblo. El laos define a la comunidad humana y el demos a la comunidad política. El pueblo es, por lo tanto, la referencia fundadora en la democracia y en la laicidad.

La laicidad al igual que la democracia comparten elementos interdependientes para la formación del ciudadano. Si se pretende formar en la democracia, la laicidad debe estar siempre presente y manifiesta. El ex Secretario de Educación Pública (19952000) Miguel Limón Rojas afirmó en el coloquio ${ }^{3}$ Laicidad y valores en un Estado democrático:

La educación para la democracia implica capacitar al ser humano, para discernir, para optar, para comprometerse consigo mismo y con los demás, para mejorarse continuamente. Esto sólo es posible en un ambiente de libertad, de libertad de conciencia, de la cual la educación laica es sostén y salvaguarda. (Blancarte, 2000, p. 30)

Cualquier sistema educativo que se declarare democrático deberá también, por consecuencia, ser laico aunque no lo exprese literalmente; ya que, la plena ejecución de la democracia implica el establecimiento de la esencia de la laicidad en los procesos escolares.

La fracción II del artículo tercero constitucional establece que la educación luchará contra la ignorancia y sus efectos, las servidumbres, los fanatismos y los prejuicios. Más adelante, los incisos indican los lineamientos de la formación en la educación:

- El inciso "a" establece que el criterio que orientara a la educación será democrático, entendido como un sistema de vida fundado en el constante mejoramiento económico, social y cultural del pueblo, es decir del demos y del laos en su conjunto: democracia y laicidad.

3. El coloquio realizado en El Colegio de México el 6 de abril de 2000, es considerado como uno de los primeros encuentros donde se analizó la laicidad y su relación con la educación, la democracia y los valores, así como los riesgos a los que se podría enfrentar. 7 años después, Rodolfo Vázquez, (Vázquez, 2007) retoma y analiza los resultados de ese coloquio retomando los diferentes elementos con que se relaciona la laicidad en su libro, (compilación) "Laicidad, una asignatura pendiente." 
- El inciso "b" que muestra que el aspecto nacional de la educación nos refiere a la república -la res publica- es decir, nos refiere al bien común al enfatizar que no debe haber hostilidades ni exclusivismos. Nuevamente se observan características compartidas de la democracia y la laicidad.

- El inciso "c" señala a la convivencia humana derivada del aprecio por la dignidad de la persona (respeto), la convicción por el interés general de la sociedad (el laos de donde se deriva el bien común), la igualdad de derechos de todos los hombres y evitar privilegios de razas, religión, de grupos, de sexos o de individuos (igualdad); todos ellos, aspectos que encontramos interrelacionados entre la democracia y la laicidad.

Al promover la laicidad, ineludiblemente se promueve la democracia, por ser estos, conceptos interdependientes. La educación que imparta un Estado democrático debe ser laica, a pesar de que no se encuentre estipulada literalmente, pues por el sólo hecho de ser democrática y de responder al bien común, implica establecer los principios de la laicidad.

Es interesante notar que, no solamente el artículo tercero constitucional muestra la tendencia por educar y vivir en la democracia, otros artículos confirman este anhelo del Estado por establecer a la democracia como una forma de vida:

- Artículo 10: Queda prohibida toda discriminación motivada por origen étnico o nacional, el género, la edad, las capacidades diferentes, la condición social, las condiciones de salud, la religión, las opiniones, las preferencias, el estado civil 0 cualquier otra que atente contra la dignidad humana y tenga por objeto anular 0 menoscabar los derechos y libertades de las personas.

- Artículo 4\%: El varón y la mujer son iguales ante la ley. Esta protegerá la organización y el desarrollo de la familia.

- Artículo 60: La manifestación de las ideas no será objeto de ninguna inquisición judicial o administrativa, sino en el caso de que ataque a la moral, los derechos de tercero, provoque algún delito, o perturbe el orden público; el derecho de réplica será ejercido en los términos dispuestos por la ley. El derecho a la información será garantizado por el Estado.

- Artículo $7^{\circ}$ : Es inviolable la libertad de escribir y publicar escritos sobre cualquier materia. Ninguna ley ni autoridad pueden establecer la previa censura, ni exigir 
fianza a los autores o impresores, ni coartar la libertad de imprenta, que no tiene más límites que el respeto a la vida privada, a la moral y a la paz pública. En ningún caso podrá secuestrarse la imprenta como instrumento del delito.

- Artículo 9: No se podrá coartar el derecho de asociarse o reunirse pacíficamente con cualquier objeto lícito; pero solamente los ciudadanos de la República podrán hacerlo para tomar parte en los asuntos políticos del país. Ninguna reunión armada, tiene derecho de deliberar.

- Artículo 12: En los Estados Unidos Mexicanos no se concederán títulos de nobleza, ni prerrogativas y honores hereditarios, ni se dará efecto alguno a los otorgados por cualquier otro país.

- Artículo 24: Todo hombre es libre para profesar la creencia religiosa que más le agrade y para practicar las ceremonias, devociones o actos del culto respectivo, siempre que no constituyan un delito o falta penados por la ley. El Congreso no puede dictar leyes que establezcan o prohíban religión alguna.

- Artículo 25: Corresponde al Estado la rectoría del desarrollo nacional para garantizar que éste sea integral y sustentable, que fortalezca la Soberanía de la Nación y su régimen democrático y que, mediante el fomento del crecimiento económico y el empleo y una más justa distribución del ingreso y la riqueza, permita el pleno ejercicio de la libertad y la dignidad de los individuos, grupos y clases sociales, cuya seguridad protege esta Constitución.

- Artículo 130: El principio histórico de la separación del Estado y las iglesias orienta las normas contenidas en el presente artículo. Las iglesias y demás agrupaciones religiosas se sujetarán a la ley.

- Artículo 130, Inciso e: Los ministros no podrán asociarse con fines políticos ni realizar proselitismo a favor o en contra de candidato, partido o asociación política alguna. Tampoco podrán en reunión pública, en actos del culto o de propaganda religiosa, ni en publicaciones de carácter religioso, oponerse a las leyes del país o a sus instituciones, ni agraviar, de cualquier forma, los símbolos patrios. (Constitución política, 2015)

El Estado laico se ha convertido, en una pieza fundamental de la democracia. A mediados de 2007, el ex-rector de la Universidad Nacional Autónoma de México (UNAM), Juan Ramón de la Fuente, declaró a los medios de comunicación que sin 
laicidad no hay democracia. Alain Touraine afirma, por su parte, que el fundamento de la democracia en la sociedad moderna es el principio de la laicidad, pues acentúa el reconocimiento de los derechos personales (Touraine, 2005:201).

La laicidad ha dejado de pasar desapercibida y se ha iniciado su reconocimiento como un elemento esencial de la democracia y para la convivencia social armónica. De tal manera que:

La idea de laicidad apunta precisamente a una unidad primaria del pueblo soberano, fundada en la estricta igualdad de derechos de sus miembros. Se subraya así la referencia al bien común, a la república, como fundamento y horizonte de la democracia. (Peña, 2002, p. 20)

La laicidad, al igual que la democracia, son formas de vida en las que el bien común, la libertad, la igualdad y el respeto a la diferencia conforman la base de la convivencia social armónica. Si se asume una forma de vida democrática, la laicidad debe ser un elemento interdependiente para la ejecución plena de la democracia.

La laicidad promueve la igualdad y el bien común que son también las bases de la democracia; además, al promover la libertad de conciencia capacita a los agentes para la toma de decisiones basados en la crítica y la reflexión, indispensables para la democracia. La laicidad entendida como comunidad humana es indispensable para pensar en la democracia como comunidad política. Así, una elección basada en los supuestos de la democracia no podría proceder si no se toma en cuenta a la comunidad humana; por ejemplo, resultaría antidemocrático convocar a elecciones en México para proclamar una religión oficial; puesto que, la mayoría de la población practica una sola religión y obviamente ganarían. La laicidad establece al bien común como base de acción de la democracia por medio del establecimiento de los límites entre lo público y lo privado.

\section{La formación de valores laicos}

En la educación primaria los valores que se pretenden que los alumnos asuman como parte de su formación y de su actuar, son valores inherentes a la democracia, valores que promueven el desarrollo del pensamiento crítico y de la libertad de conciencia. Los ejes formativos de la asignatura "Formación Cívica y Ética" muestran su desprendimiento del artículo tercero constitucional y este a su vez de una filosofía laica y democrática, sin embargo y a pesar de estar presente, no se hace mención 
explícita de la laicidad como concepto que contiene y provee los valores fundamentales para la formación cívica del agente, lo que no sucede con la democracia cuya función se explica de manera más amplia.

Los valores que busca promover la asignatura de educación cívica son los que la humanidad ha creado y consagrado como producto de su historia:

- Respeto y aprecio por la dignidad humana

- Libertad

- Justicia

- Igualdad

- Solidaridad

- Tolerancia

- Honestidad

- Apego a la verdad

Todos estos elementos se desprenden de la democracia cuyos principios encontramos en la laicidad y apuntan hacia el bien común. Estos valores proceden de una concepción exigente de la igualdad humana; son valores que no pueden ser catalogados como religiosos o antirreligiosos, por lo que los podemos adjetivar como "valores laicos". Estos pueden promoverse como elementos comunes a todos sin importar la convicción religiosa o filosófica de los alumnos y docentes. Los valores laicos sustentados en la democracia y en el bien común, permanecen separados de toda doctrina religiosa y filosófica, por lo que todos podemos ser formados bajo estos valores. Ante el creciente número de conflictos de origen religioso en las escuelas primarias, resulta indispensable la formación explícita en la laicidad como norma de vida, en cuyos valores nos podemos identificar todos sin importar la convicción religiosa o filosófica.

Los valores laicos son también la respuesta a la inquietud y preocupación de la jerarquía católica en México ante lo que ellos identifican como "pérdida de valores en la sociedad" y sus intenciones de enseñar moral religiosa católica en las escuelas. Con esto se pone fin a una discusión infundada de que la laicidad carece de moral. El ex secretario de la SEP (1995-2000) Miguel Limón Rojas declaró en el coloquio Laicidad y valores en un Estado democrático: "La laicidad significa neutralidad en materia religiosa, pero no neutralidad valorativa o moral. No sólo permite sino estimula una educación valoral" (Limón en Blancarte, 2000, p. 27). Así, los alumnos 
católicos, testigos de Jehová, protestantes, evangélicos, cristianos, mormones, ateos, agnósticos, pueden tener valores comunes que los unan más allá de las diferencias espirituales.

El Obispo de Colima el 22 de Julio de 2008 declaró que "el laicismo es una tendencia que fija su objetivo en los aspectos materiales como la única parte importante en el ser humano". Según esta opinión no se ve aun las potencialidades y los elementos que ofrece la laicidad para convivencia armónica, probablemente de verse así, superan por mucho, incluso, algunas propuestas religiosas para la formación de valores en la escuela.

Los valores laicos reúnen las características de la democracia y del bien común, que coinciden con los que se encuentran en la Declaración Universal de los Derechos Humanos. Los valores religiosos, por no ser parte del bien común, no pueden considerarse para la formación de valores en la escuela primaria, ya que son y siempre serán parte del ámbito privado en el que las diferentes religiones deben ocuparse para promoverlos entre sus fieles sin necesidad de pedir ayuda al Estado 0 a la escuela.

La laicidad nos permite establecer valores laicos y democráticos como parte del bien común de la sociedad, en el entendido de que una religión o una filosofía no pueden considerarse como un aspecto común en todos los mexicanos ya que actualmente existen más de 500 asociaciones religiosas registradas en la Secretaría de Gobernación y tratar de elegir una por encima de las demás, quebrantaría la igualdad que la laicidad esta llamada a promover.

La educación laica fomenta una cultura nacional incluyente, en la que conviven los distintos modos de entender la vida en una sociedad plural. La educación laica no tiene como finalidad atacar a las religiones ni luchar contra las enseñanzas espirituales provenientes del hogar y de las religiones; busca educar bajo los principios de la democracia y del bien común, en donde los alumnos con diferentes creencias, se reúnan para aprender, adquirir y fortalecer valores que le permitan una sana convivencia en un Estado democrático cuya sociedad es cada vez más plural.

\section{La formación del pensamiento crítico}

Una más de las potencialidades de la laicidad en la escuela, es la formación del pensamiento crítico en el alumno, ideal por el cual se ha luchado por alcanzar sin 
lograr un avance significativo. La escuela laica debe instruir hacia la libertad a menores que en el plano civil no son todavía sujetos jurídicos con estatuto de ciudadanos. Henri Peña afirma que la laicidad libera el pensamiento crítico (Peña, 2002, p. 476). Y el pensamiento crítico nos permite analizar, reflexionar, criticar y decidir.

Por su parte, Miguel Limón Rojas menciona:

La escuela tiene la obligación de brindarle a los alumnos las herramientas conceptuales y de juicio que progresivamente lo ayuden a examinar por su propia cuenta el conjunto de los principios que guían su conducta, para sostenerlos o modificarlos según los criterios que libremente vaya formando en su proceso de maduración, de modo que pueda hacer compatibles sus convicciones con los imperativos de la convivencia y se encuentre en aptitud de hacer valer su libertad de conciencia ante la sociedad. (Limón en Blancarte, 2000, p. 26)

La escuela no es el lugar donde se examinan las creencias de los educandos, sino un espacio enmarcado por valores que hacen posible la convivencia de personas con diferentes religiones o sin estas La libertad de conciencia, parte esencial de la laicidad; libera al agente de todo sometimiento ideológico o espiritual que le impide analizar otras ideas, comparar, criticar, elegir y relacionarse con quienes tengan una creencia diferente.

Recordemos que a lo largo de la historia, la jerarquía católica ha sido la principal protagonista en contra de la promoción de la libertad de conciencia, aunque, no la única. Juan Pablo II condenó a los curas revolucionarios y a la Teología de la Liberación desarrollada en América Latina; el Papa Pío IX en 1864 condenó la libertad de conciencia considerándola anatema ${ }^{4}$. Además, en el Syllabus, anexo a la Encíclica Quanta Cura, también se consideraba anatema a todo aquel que afirmara cualquiera de las siguientes expresiones liberales:

- Art. XI: todo hombre es libre de abrazar y profesar la religión que considere verdadera según la luz de su razón.

- Art. LXXVII: en nuestra época ya no es útil que la religión católica sea considerada como única religión del Estado con exclusión de todos los demás cultos.

4. Significa "maldito", en el sentido de ser condenado a ser apartado o separado de una comunidad de creyentes. Era una sentencia mediante la cual se expulsaba a un hereje del seno de la sociedad religiosa; era una pena aún más grave que la excomunión. 
- Art. LXXVIII: es también de razón que en algunos países católicos la ley haya establecido que los extranjeros que se trasladen allí gocen del ejercicio público de sus cultos particulares.

- Art. V, proposición 24: La iglesia no tiene derecho a usar la fuerza.

- Art. LXXIX: En efecto, es falso que la libertad civil de todos los cultos y los plenos poderes acordados a todos de manifestar abierta y públicamente todas sus ideas y opiniones contribuyan a corromper las costumbres, a pervertir las mentes de los pueblos y a probar la peste de la indiferencia. (Peña, 2001, p. 53)

Cualquiera que manifestara alguna de las anteriores expresiones llenas de libertad de conciencia, de igualdad y de liberación del poder temporal, sería considerado como anatema por el simple hecho de hacer uso de la razón. Quizás, este sea uno de los principales motivos del rechazo que la jerarquía católica y otros líderes religiosos siempre han mostrado contra la laicidad. ¿Será que el uso de la razón y la libertad de conciencia que derivan en un pensamiento crítico lleven a los que se les impuso una religión a reflexionar, criticar y decidir por una opción religiosa diferente?

Cuando existe formación en la libertad de conciencia, en la igualdad, en el bien común, en el respeto a la diversidad, y en el análisis que lleve a la reflexión (todos estos, elementos presentes en la laicidad) se da como resultado el desarrollo del pensamiento crítico, indispensable para la vida en democracia al momento de decidir las mejores alternativas para el mejoramiento de la vida en sociedad. Además, el pensamiento crítico logra la emancipación de la dominación clerical y se adquiere la capacidad de decidir para permanecer o cambiar de acuerdo a convicciones y no a imposiciones.

Cuando las escuelas imponen una determinada convicción religiosa o filosófica, están actuando contra la libertad de conciencia y consecuentemente impiden la formación del pensamiento crítico, indispensable para que el ciudadano desarrolle la capacidad de analizar y decidir. La laicidad contribuye a emancipar al agente, a que reconozca y acepte la diversidad religiosa, a ver al otro como su igual, a decidir por sí mismo acerca de sus convicciones espirituales o filosóficas y a manifestarlas en el ámbito privado sin buscar imponer sus ideas ni condenar a quien piense diferente.

El pensamiento crítico formado en la laicidad, también promueve el análisis de temas controversiales en la escuela como el aborto, la anticoncepción, la teoría de la evolución y la educación sexual, pues asegura en el alumno la separación de lo 
público y lo privado, llevándolo a respetar lo que se enseña en al ámbito público (la escuela) sin renunciar a sus concepciones privadas (religiosas o filosóficas).

La misión de la escuela, no es formar ciudadanos antirreligiosos, agnósticos, religiosos o ateos; puesto que, eso corresponde estrictamente al ámbito privado de cada persona. Como se analizó en el enfoque de educación cívica, el criterio que orienta a la educación está basado en aspectos del ámbito público, del bien común, de la democracia, aspectos en los que todos, a pesar de las diferentes convicciones, podamos vivir en armonía separando lo público de lo privado.

El desarrollo del pensamiento crítico-reflexivo que promueve la educación laica, no se limita a liberar al agente de posibles imposiciones religiosas o filosóficas, sino también ideológicas que le impiden analizar y decidir sobre aspectos importantes de la vida en sociedad como son las elecciones políticas. Cuando no se ha desarrollado el pensamiento crítico en el ciudadano, resulta muy fácil manipularlo con spots televisivos que son considerados por muchos como "la verdad". El pensamiento crítico promueve el análisis, la crítica, la reflexión y la comparación; aspecto que resulta indispensable para el ejercicio pleno de la democracia.

La laicidad, además de contribuir a la formación en y para la democracia, promueve los valores y el pensamiento crítico en el alumno, indispensable para combatir la ignorancia y sus efectos, las servidumbres, los fanatismos y los prejuicios. La educación laica esta llamada a emancipar por medio del análisis, la crítica y la reflexión que la libertad de conciencia promueve y que es parte esencial de la laicidad.

\section{Discernimiento entre los ámbitos público y privado}

¿Cómo procurar la igualdad en la escuela de hoy en la que se reúnen alumnos y docentes con diferentes convicciones religiosas y filosóficas? ¿Cómo procurar la convivencia armónica entre ellos?

La educación laica nos proporciona una alternativa muy viable para dar la respuesta a las necesidades de convivencia en la escuela multicultural de hoy. Para ello es necesario promover los elementos de la laicidad como un concepto que necesita de la puesta en acción de todos sus elementos y no sólo de algunos. Los valores laicos, la libertad de conciencia, el pensamiento crítico y el bien común se conjugan para consolidar la convivencia armónica entre alumnos y docentes. 
La formación en la laicidad le permite al alumno diferenciar entre lo público y lo privado así como entre lo colectivo y lo particular, lo que contribuye a distinguir entre lo que es de todos (el bien común, lo público) de lo que es de algunos (lo privado, ya sea individual o colectivo); para el caso de las diferentes formas de pensar y de los alumnos con diferentes convicciones espirituales o sin ellas, resulta indispensable fortalecer esta distinción para procurar la tolerancia, el respeto y el reconocimiento a la diversidad.

Uno de los elementos de la laicidad es el bien común que a su vez se ubica en el ámbito público. Lo privado será válido siempre y cuando no intente formar parte del bien común. Lo público son todos aquellos aspectos que pueden ser comunes y aplicables a todos los ciudadanos de una sociedad, y lo privado siempre será lo referente a las convicciones personales que cada individuo en pleno uso de su libertad está facultado a ejercer.

En el ámbito privado se expresan las convicciones personales, aquellas que el agente decide adoptar y seguir como norma de vida personal. Aquí se encuentran las diversas religiones y filosofías, así como todas aquellas decisiones individuales emanadas del uso de la libertad. En el ámbito público se manifiestan todos aquellos aspectos que son comunes y aplicables a todos los ciudadanos. Forman parte del ámbito público: la Constitución, las leyes, la identidad nacional, la moneda y el Estado de derecho. En suma, todos los aspectos en los que se identifican los mexicanos.

Las expresiones del ámbito privado, pueden ser individuales o colectivas, sin embargo, la expresión colectiva de las mismas no las convierte en aspecto del ámbito público. La laicidad establece los límites entre lo público y lo privado. Lo que es solo de algunos, aunque represente a la mayoría no puede ser impuesto a todos cuando este procede del ámbito privado. Cuando los agentes escolares comprenden que no es correcto tratar de imponer las ideas que pertenecen al ámbito privado, se encuentran con mayores posibilidades de establecer un dialogo en el ámbito público sin tocar sus propias subjetividades; esto es lo que muchos llaman ser objetivo.

Cuando el alumno es enseñado a identificar lo que es de todos de lo que es de algunos (ámbitos público y privado), se encuentra en mejor disposición de comprender que existen aspectos derivados de convicciones personales que no se deben imponer a otros ni se debe condenar a quien tenga otras convicciones diferentes. Aspectos ante los cuales debe adoptar una postura de respeto y aceptación, aunque no se esté de acuerdo con las convicciones diferentes, esto es, que el alumno aprenda a ser tolerante. 
Al diferenciar lo público de lo privado, el alumno identifica los aspectos comunes en los que todos los mexicanos, sin importar las diferencias, podemos basarnos para convivir en armonía. Este ha sido el papel de la escuela laica, ser una escuela para todos, un espacio donde se reúnen diferentes convicciones religiosas o filosóficas para convivir en aspectos comunes a todos como la educación.

El bien común, la libertad de conciencia y la formación del pensamiento crítico, todos ellos provenientes de la laicidad, establecen los límites entre lo público y lo privado con el fin de promover el respeto y la tolerancia.

\section{Fortalecimiento de la identidad nacional}

La laicidad permite distinguir entre lo que es de todos de lo que es de algunos (lo público y lo privado), imprescindible para identificar los aspectos que han de delimitar la noción de identidad de todos los mexicanos y no solo de algunos. La educación laica procura la formación de una identidad nacional como lo pretende la asignatura Formación Cívica y Ética donde el alumno se reconozca como parte de una comunidad nacional donde existe pluralidad de pensamientos, diversidad religiosa, diversidad cultural y diversidad social, pero que dentro de toda esta pluralidad, existen rasgos y valores que comparten todos, esto es, existen elementos como los valores laicos: "estos valores son: respeto y aprecio por la dignidad humana, libertad, justicia, igualdad, solidaridad, tolerancia, honestidad y apego a la verdad". Los cuales todos, en una sociedad multicultural, podemos compartir.

Un Estado laico debe basar la formación de la identidad nacional en aspectos multiculturales, pues de acuerdo a Peña: "lo que es sólo de algunos no puede imponérsele a todos" (2002, p. 9). En palabras de Roberto Blancarte:

El manejo de la identidad ciudadana en los últimos dos siglos, por lo menos en los países occidentales, se identifica con el surgimiento del Estado laico y de formas políticas de participación por medio de un común denominador, el cual ya no es necesariamente el de las creencias religiosas. Los nuevos estados nacionales han buscado, desde su fundación, la construcción de una identidad común que pase por encima de esas diferencias de convicciones. (Blancarte, 2006, p. 148)

En sociedades con creciente diversidad, la promoción de una identidad nacional religiosa ya no es la mejor vía para representarla pues la conformación de una identidad multicultural resulta ser la mejor alternativa. Los principios de la laicidad 
se encuentran presentes en la educación cívica encargada de formar la identidad nacional del ciudadano mexicano en una sociedad con pluralidad religiosa y culturas diversas que camina hacia una conformación social multicultural.

México camina hacia una conformación multicultural y los contenidos del plan y programas de estudio y el enfoque de educación cívica expresan esta cualidad para la formación de la noción de identidad basada en elementos multiculturales, es decir, en aspectos sobre los cuales todos los mexicanos nos identifiquemos, aspectos que realmente sean de todos y no solo de algunos. La identidad nacional basada en el multiculturalismo, desarrolla la pluralidad, evita la rivalidad y el conflicto entre comunidades culturales y políticas.

Si se pretende conformar un país multicultural es indispensable promover, también, la noción de identidad nacional; basada en los aspectos que la laicidad promueve cimentados en el bien común. Así como en los límites entre lo público y lo privado, todo esto como uno de los pilares que conforman la base del multiculturalismo. La laicidad se ha convertido en un elemento esencial para el establecimiento de la sociedad multicultural, como bien lo señala Touraine: "No hay multiculturalismo sin laicidad" (citado en Gutiérrez, 2006, p. 299). El cuarto aspecto de la educación cívica, indicado para tratar el fortalecimiento de la identidad nacional contiene elementos de la laicidad como son la igualdad, la libertad de conciencia y el bien común como parte del ámbito público.

La educación laica tiene un gran potencial para el fortalecimiento de la identidad nacional basada en lo estipulado por el cuarto aspecto de la educación cívica, que coincide plenamente con el contenido del artículo $3^{\circ}$ Constitucional. Si a los alumnos se les forma en la multiculturalidad, además de enseñarles que la pluralidad religiosa es una característica del México actual que nos identifica con diversas opciones religiosas y filosóficas, todo esto como parte de su identidad, podría ayudar al fortalecimiento de la tolerancia y como consecuencia, a disminuir los conflictos de origen religioso en las escuelas.

\section{Reflexiones finales}

La laicidad, además de evitar los conflictos de origen religioso en la escuela, promueve los valores, fortalece la democracia y forma el pensamiento crítico en el alumno, indispensable para combatir las servidumbres, los fanatismos y los prejuicios. 
El ideal laico permite la relación entre la fe y la razón, permite analizar y decidir respetando la diferencia sin imponer ni condenar. La educación laica necesita hacerse explícita y potencializar todas sus libertades en la formación del ciudadano democrático durante la educación básica. Si solo se retoma a la laicidad como una ley que prohíbe la enseñanza de cualquier doctrina religiosa se estaría dejado de lado su carácter formativo.

La laicidad es parte del artículo tercero Constitucional al que se hace referencia solo para mencionar su arista jurídica enfocándose a la enseñanza ajena a cualquier doctrina religiosa. Incluso los libros de texto de formación cívica y ética, no mencionan la laicidad, ni al carácter laico de la educación. En estos libros se hace énfasis en la democracia como forma de vida, en la solución dialogada de conflictos y en los valores para una vida social armónica.

Los valores que se enseñan en la escuela deben ser mostrados como parte de una unidad que corresponde al bien común y que es parte fundamental de la laicidad, que bien se podrían mostrar como valores laicos; pues, en ellos todos nos podemos identificar sin importar la creencia religiosa o filosófica que se tenga. La educación tanto pública como privada debe defender los ideales de la laicidad y la democracia como patrimonio ético común a todos los ciudadanos basados en los valores de la libertad de conciencia, la igualdad y la solidaridad entre los seres humanos.

La democracia y la laicidad se mencionan en el artículo $3^{\circ}$ como elementos que conforman la base de la educación y los criterios que la orientan; sin embargo, de estos dos elementos, la laicidad no existe como tema de análisis en el plan y programas de estudio de educación primaria a diferencia de la democracia que si ocupa un lugar preponderante en el curriculum.

La laicidad, al igual que la democracia, al ser elementos interdependientes, deben tratarse en la educación primaria de manera explícita como un tema de estudio, analizando los elementos que la conforman así como su estrecha interdependencia con la democracia.

Si se busca la formación de ciudadanos democráticos, es necesario formarlos como ciudadanos laicos. Si se busca potencializar la educación laica, es necesario hacerla explícita y establecer el tema de laicidad a la par de la democracia como los pilares de la convivencia. 
La laicidad debe salir de lo implícito e iniciar su tratamiento explícito. Tales potencialidades han estado presentes de manera constitucional desde 1917, pero han sido desaprovechadas y no se han explotado todas sus cualidades, limitándose a la separación Estado y religiones (Art.130 constitucional), cuando en realidad existen otros elementos de la laicidad que pueden impulsar la convivencia armónica como son el bien común, los límites entre lo público y lo privado, el respeto, la igualdad y la libertad de conciencia.

Si se busca potencializar la educación laica en la escuela primaria, resulta indispensable que se haga explícita; pero también es necesario que los planes y programas de estudio así lo indiquen. Como consecuencia, la formación de docentes laicos se convierte en un punto esencial, por lo que ellos también necesitarían ser formados en una laicidad explícita.

Si se continúa manteniendo a la laicidad como un concepto abstracto del que se desconocen sus elementos y del que fácilmente cualquier persona puede cambiar su significado, sus potencialidades continuarán relegadas y desaprovechadas, lo que resulta útil para los fines de los clericalismos que buscan desprestigiarla por considerarla una amenaza a la dominación de conciencia.

En cambio, si la laicidad se convierte al igual que la democracia en una forma de vida, las probabilidades de explotar al máximo sus potencialidades, entre ellas la libertad de conciencia y el bien común que llevan a la reflexión por medio del pensamiento crítico y permiten el análisis y toma de decisiones, la sociedad ampliará sus posibilidades de convivir armónicamente; pero para ello es necesario hacer explícito el tema de la laicidad en la formación de los ciudadanos mexicanos, misión que la escuela pública y privada están llamadas a cumplir.

La esencia de la educación laica tiene un gran potencial en la formación de ciudadanos emancipados, libres, capaces de ejercer un juicio crítico y decidir sin ningún sometimiento ideológico. A pesar de su oposición y de las infundadas acusaciones en su contra, el ideal laico tiene amplias posibilidades en el futuro, que podría muy bien concernir a todos los pueblos de la tierra, particularmente en nuestro país. Pronto llegará ese día.

La educación laica puede contribuir a la formación de alumnos con valores necesarios para la convivencia social, sin embargo, tal potencialidad ha sido desaprovechada por encontrarse de manera implícita en la escuela. A la fecha de noviembre de 2017, 
la laicidad no es un tema de estudio en la educación cívica. Y no lo es, porque no contamos con un régimen político que promueva un Estado democrático. Sin duda en el próximo sexenio 2018-2024 de transición a la democracia, la laicidad será un tema de primer orden porque en un régimen democrático se promueve la democracia en la escuela, el respeto a las creencias y una democracia social, más allá del respeto a voto de los ciudadanos, fomentaremos una democracia como forma de vida económica, social y cultural de todas las clases sociales.

\section{Conclusiones}

1. La educación laica no es únicamente una educación ajena a cualquier doctrina religiosa; sino también, una educación sustentada en principios que implican profunda consideración de la libertad y de la justicia.

2. La laicidad promueve la igualdad y el bien común que son también base de la democracia; además, al promover la libertad de conciencia capacita a los agentes para la toma de decisiones basados en la crítica y la reflexión, indispensables para la democracia.

3. Una más de las potencialidades de la laicidad en la escuela es la formación del pensamiento crítico en el alumno, ideal por el cual se ha luchado por alcanzar sin lograr un avance significativo. La escuela laica debe instruir hacia la libertad a menores que en el plano civil no son todavía sujetos jurídicos con estatuto de ciudadanos.

4. La educación laica proporciona una alternativa muy viable para dar la respuesta a las necesidades de convivencia en las escuelas multiculturales de hoy.

5. La educación laica necesita hacerse explícita y potencializar todas sus libertades en la formación del ciudadano democrático durante la educación básica. Si solo se retoma a la laicidad como una ley que prohíbe la enseñanza de cualquier doctrina religiosa se estaría dejado de lado su carácter formativo. 


\section{REFERENCIAS}

Bauberot, J. (2005). Historia de la laicidad francesa. México D.F:: El Colegio Mexiquense.

Blancarte, R.(2000). Laicidad y valores en un estado democrático. México, México D.F.: COLMEX-SEGOB.

Constitución Política de los Estados Unidos Mexicanos de 1917. https://www.solon. org/Constitutions/Mexico/Spanish/constitution-mex.html (consultado en noviembre, 2018)

Gutiérrez, D. Coord. (2006). Multiculturalismo. Desafíos y perspectivas. México D.F: COLMEX-UNAM-Siglo XXI.

Peña, H. (1999). La emancipación laica, filosofía de la laicidad. España, Madrid: Laberinto colección Hermes.

Peña, H. (2002). La laicidad. México D.F.:. Siglo XXI

Touraine, A.(2005). Un nuevo paradigma para comprender el mundo de hoy. España, Barcelona: Paidós. 